\title{
La falsa atribución de la autoría de una obra en los trabajos de investigación científica
}

\author{
Juan Espinoza Espinoza \\ Abogado por la Universidad Nacional Mayor de San Marcos. \\ Máster en Derecho con mención en Derecho Civil por la \\ Universidad Nacional Mayor de San Marcos. \\ Doctor en Derecho por la Pontificia Universidad Católica del Perú. \\ Profesor de Derecho Civil en las Facultades de Derecho \\ de la Universidad Nacional Mayor de San Marcos, \\ Pontificia Universidad Católica del Perú \\ y de la Universidad de Lima. \\ Presidente del Tribunal de Controversias del Organismo \\ Supervisor de la Inversión en Infraestructura de \\ Transporte de Uso Público (OSITRAN), del \\ Consejo de Notariado y del Consejo de Supervigilancia de Fundaciones.
}

SUMARIO:

I. Introducción.

II. Los Derechos de Autor.

III. Reseña histórica sobre los derechos de autor.

IV. Teorías sobre la naturaleza jurídica de los derechos de autor:

1. Teoría de la propiedad;

2. Teoría del derecho del trabajo;

3. Teoría de la personalidad;

4. Teoría de la colectividad;

5. Teoría de los Derechos Intelectuales;

6. Teoría del Doble Derecho:

6.1. Derechos Morales;

6.2. Derechos Patrimoniales.

V. Los derechos de autor en la legislación peruana.

VI. Los derechos de autor en la experiencia jurisprudencial administrativa nacional.

VII. Un caso insólito: el plagio en una sentencia.

VIII. Reflexiones Finales. 


\section{INTRODUCCIÓN}

Resulta lamentable constatar que los trabajos de investigación jurídica adolecen de serias deficiencias. La más lamentable es la poca seriedad con la cual se manejan las fuentes de información, haciendo presentar como idea propia la ajena.

Esta investigación pone a la luz diversos casos en los cuales se atribuye falsamente la autoría, a efectos de tomar conciencia de este problema y que investigadores y asesores asuman los roles y responsabilidades que les corresponden.

Se constata que la falsa atribución de la autoría es un problema generalizado, entre otros, a nivel de redacción de sentencias, con escritores reconocidos y en el campo de la investigación jurídica.

Iniciaré el recorrido de esta investigación, definiendo los derechos de autor:

\section{LOS DERECHOS DE AUTOR}

Los denominados derechos de autor forman parte de los derechos intelectuales y están compuestos por dos grupos de derechos: los derechos patrimoniales, en los cuales se tutela la disposición de la obra y los derechos personales, en los cuales se tutela una serie de situaciones jurídicas destinadas a proteger la atribución de la paternidad intelectual del autor con respecto a la obra, así como la integridad de la misma.

\section{RESEÑA HISTÓRICA SOBRE LOS DERECHOS DE AUTOR}

Grecia podría ser la cuna del primigenio y elemental concepto de estos derechos. Aunque faltaban disposiciones legales sobre la materia, se llegó a determinar como acto reprochable el plagio. En Roma se llega a definirlo concretamente como la actio iniuriarum o la acción deshonesta. En Roma tampoco existían disposiciones legales, por lo tanto no se era condenado por los tribunales, sino más bien por la opinión pública. Inglaterra, a diferencia de los pueblos anteriores, reconoció los derechos de autor y se convirtió de esta manera en la primera nación en regular tales derechos. A fines del siglo XVII, Locke los fundamenta jurídicamente como derechos adquiridos por el trabajo intelectual. En 1709, Worthely consiguió que en la Cámara de los Comunes se sancionara un bill que fue aprobado por la reina Ana de Estuardo el 10 de abril de 1710. Estados Unidos sigue en el planteamiento filosófico a Inglaterra y, de esta manera, su Estado de Carolina del Norte declaró en su Constitución: «Por cuanto nada es más estrictamente propio de un hombre que el fruto de su pensamiento». España, con Carlos III en 1763, declara tales derechos, pero el verdadero aporte se encuentra en el establecimiento del régimen sucesorio de los privilegios para los herederos del autor. La Revolución Francesa hace su aporte al enriquecimiento de estos derechos al prohibir la reproducción de obras de autores vivos sin autorización, reconociéndose de esta manera el «derecho de propiedad del autor».

\section{TEORÍAS SOBRE LA NATURALEZA JURÍDICA DE LOS DERECHOS DE AUTOR}

No son pocos los tratadistas que pretenden delinear la esencia de estos derechos. Un sector de la doctrina española, aborda el problema desde una perspectiva más amplia, partiendo de la naturaleza de los derechos intelectuales, entendidos estos últimos como "los diferentes tipos de derechos subjetivos que los ordenamientos jurídicos modernos atribuyen a los autores de creaciones espirituales (obras de arte y literatura e invenciones) y a los industriales y comerciantes que utilizan signos determinados para identificar los resultados de su actuación y preservar, frente a los competidores, los valores espirituales y económicos incorporados a su empresa (nombres comerciales y marcas)" ${ }^{\prime 1}$. La relación entre derechos intelectuales y derechos

1. BAYLOS CORROZA, Hermenegildo. Tratado de Derecho Industrial, Civitas, Madrid, 1978, p. 43. 
de autor es de género a especie. Se distingue dentro del derecho del autor a las posiciones dualistas, vale decir "aquellas que escinden el derecho sobre creaciones intelectuales, en dos tipos de derechos diferentes, que no deben ser confundidos, aunque manifiestan entre sí relaciones e incluso interferencias recíprocas: El derecho moral y el derecho patrimonial del autor"2, de las teorías monistas, cuya característica común es "la interpretación unitaria de cuantas facultades y derechos posee el autor, que no son más que derivaciones, manifestaciones y modalidades de una figura única. Podrán reconocerse en ella sectores diferentes de prerrogativas, distintos grupos de facultades. Pero es después de admitir que forman parte de un derecho subjetivo que ha de construirse en forma unitaria; todas ellas no son más que la manifestación del señorío jurídico que corresponde al autor sobre su obra, los medios para hacer efectivo y garantizar ese señorío y ese poder de disposición en todas las manifestaciones y referido a todos los valores que la obra representa para el autor" ${ }^{\prime \prime}$. Cabe anotar que, para este autor, dentro de las teorías monistas, se encuentra aquella que entiende al autor como un doble derecho, que en realidad es un "derecho que está integrado por dos clases de facultades, lo constituyen dos facetas diferentes, la personal y la patrimonial"4

Basado en la clasificación de la doctrina que vengo siguiendo y la de un sector de la doctrina nacional ${ }^{5}$, propongo la siguiente:

\section{Teoría de la propiedad}

Los seguidores de esta teoría consideran que el derecho de autor está inmerso en el derecho de propiedad. De esta manera, el derecho de autor quedaría absorbido por los derechos reales. Esta tesis fue negada y ha sido signada por Edmond Picard como una «herejía jurídica».

Se advierte que "puede comprenderse ya que la doctrina de la propiedad no se profesa por los distintos autores de manera unívoca. Quién acude a extraer de ella solamente su significado metafórico; quién, por el contrario, utiliza el concepto de un modo podríamos decir que literal; sucediendo que pueden registrarse casi versiones tan distintas como opinantes, aunque todas ellas coincidan en la adopción del concepto. También en la enunciación de la tesis han de distinguirse etapas. La evolución del pensamiento jurídico y el advenimiento de concepciones nuevas para explicar la naturaleza jurídica de las instituciones ha como decantado la tesis de la propiedad, alejándola de sus primitivas fórmulas, demasiado simplistas e incluso ingenuas y remozándolas conceptualmente" ${ }^{\prime \prime}$.

Como objeciones a esta posición, se han enunciado las siguientes ${ }^{7}$ :

a) El objeto de los derechos de autor es una actividad de alguien, mientras que el del dominio es la cosa misma, considerada en su totalidad.

b) En el derecho de autor no cabe hablar propiamente de disfrute, sino de obtención de ganancias.

c) El carácter del derecho del autor es negativo y excluyente, vale decir, hace impedir que cualquier persona distinta del titular lleve a cabo esa misma actividad de reproducción o explotación de la obra. Cosa que sí es aplicable cuando el propietario cede a otro su ius fruendi.

2. BAYLOS CORROZA, Hermenegildo. op. cit., p. 393.

3. BAYLOS CORROZA, Hermenegildo. op. cit., p. 460.

4. BAYLOS CORROZA, Hermenegildo. op. cit., p. 459.

5. PIZARRO DÁVILA, Edmundo. Los Bienes y Derechos Intelectuales. Derechos Intelectuales sobre obras Literarias y Artísticas, Tomo I, Editorial Arica S.A., Lima, 1974, p. 27 y ss.

6. BAYLOS CORROZA, Hermenegildo. op. cit., p. 399.

7. BAYLOS CORROZA, Hermenegildo. op. cit., pp. 409-413. 
d) La Administración pública interviene en la adquisición del derecho del autor, cosa que no sucede, necesariamente, en el derecho de propiedad.

Algunos autores advierten que se presenta en el derecho de autor la "reivindicación», típico medio de defensa de la propiedad. Este argumento ha sido rebatido por Piola Caselli, quien siguiendo a lhering, afirma que la acción propia característica en defensa del derecho de autor, en su aspecto pecuniario, es la acción infractoria o contrafactoria, sea que se plantee como interdictoria o como acción de daños, la cual es distinta a la acción reivindicatoria que está principalmente dirigida a recuperar la cosa material ${ }^{8}$.

\section{Teoría del derecho del trabajo}

Se sostiene que el derecho de autor no es más que una manifestación del trabajo humano y por consiguiente, las retribuciones a que éste tiene derecho son sobre la base de su esfuerzo personal. Sin embargo, "la doctrina del derecho del trabajo no puede ser aceptada, si se tiene en cuenta que el derecho de los creadores no recae ni sobre su persona ni sobre su actividad, sino sobre una entidad exterior, que es la creación intelectual. El autor no es un trabajador, sino un creador de la obra, que son conceptos totalmente diversos. No es posible incluir la protección al autor considerándolo como un trabajador más a quien hay que retribuir por el esfuerzo. Existirán indudablemente consideraciones de tipo sociológico que apoyen una tendencia de esta naturaleza; en otras palabras, podría ser muchas veces más interesante desde un punto de vista económico para los autores que la ley les dedicase un tipo de tutela específicamente laboral, garantizándoles unas condiciones determinadas de carácter económico, que no el que siga considerándolos como empresarios de sí mismos, que es lo que fundamentalmente caracteriza a este tipo de derechos. Pero aún cuan- do desde un punto de vista material resultasen gananciosos los autores, es evidente que en ese caso la protección se disolvería en medidas sociales muy diferentes de las que constituyen el contenido específico de estos institutos" ${ }^{\prime \prime}$.

\section{Teoría de la personalidad}

Esta tesis fue defendida por Otto von Gierke. Este civilista alemán, siguiendo a Kant, sostiene que el derecho de autor es producto de la acción personalísima de la invención, de la creación. De este derecho surgen una serie de facultades, como la de mantener la obra inédita, o difundirla. Por su naturaleza, dichas facultades no tienen un carácter económico, sino más bien, corresponden a un auténtico derecho de la persona. En efecto, el objeto del derecho de autor "es una obra espiritual que, gracias a su individualización, tiene una existencia especial; gracias a su fijeza exterior, una existencia independiente, y gracias a su condición de bien incorporal, un valor propio"10.

Al ser la obra, para Gierke, una prolongación de la persona de su autor, no cabe la idea de desligar la primera del segundo. Podrá haber cesión del ejercicio del derecho sobre la obra, mas no sobre la obra misma. Ihering afirma que con la creación de la obra se exterioriza la personalidad del autor. Por eso el derecho de autor no protege la personalidad, pero sí el poder jurídico entre el autor y la obra. Esta posición resulta muy imprecisa, por cuanto no brinda una cabal respuesta sobre la transmisión de los derechos de autor, tanto inter vivos como mortis causa. No obstante esta crítica, como otras, el acierto de Gierke está "en haber sabido poner de manifiesto el fundamento de la protección que se dispensa al autor. La esencia radical del derecho, que es evidentemente de naturaleza ideal, el carácter complementario de toda derivación patrimonialista a que el derecho pueda dar lugar o que origine; la construcción monista del derecho, en resumen"11.

\footnotetext{
8. PIZARRO DÁVILA, Edmundo. op. cit., p. 28.

9. BAYLOS CORROZA, Hermenegildo. op. cit., p. 470.

10. VON GIERKE, Otto. citado por Hermenegildo BAYLOS CORROZA, op. cit., p. 461.

11. BAYLOS CORROZA, Hermenegildo. op. cit., p. 468.
} 


\section{Teoría de la colectividad}

Esta teoría fue enunciada por Colin y Capitant, acogiendo las ideas socialistas francesas. Parte del supuesto de que las obras de arte y los inventos son patrimonio de la humanidad, porque es ésta a la cual benefician. De Boor manifiesta que las obras del espíritu no pertenecen a sus creadores, porque su realización ha dependido de la cultura nacional, en la cual éstos se encuentran inmersos ${ }^{12}$.

Nadie discute que pisamos un suelo cultural, que se ha ido sedimentando de los aportes de hombres y mujeres, durante generaciones. El hombre es bidimensional, es un ser único e irrepetible, pero vive en sociedad y no se le puede concebir fuera de ésta. Lo mismo ocurre con las obras de su invención: pertenecen a su mentor, que ha necesitado de experiencias anteriores y ajenas para la creación de un objeto con características propias y originales, que no puede ser atribuible a ningún otro sujeto, ya sea considerado individual o colectivamente.

No aceptar este hecho, vale decir, negar al hombre tanto su «ser» como su «hacer», particularmente entendido este último como el producto de su invención, implica, irremediablemente, negar al ser humano ser quien es: es ir en contra de su identidad personal.

\section{Teoría de los Derechos Intelectuales}

Fue defendida por Edmond Picard, abogado de la Corte Suprema de Bélgica, en 1879. Picard manifiesta que la clasificación tripartita venida del Derecho Romano (personas, reales y obligaciones), era incompleta y había que agregarle como cuarto término «los derechos intelectuales». En efecto, la naturaleza del derecho intelectual es distinta, la producción del espíritu no puede ser confundida con un trozo de materia, y por lo tanto el ordenamiento jurídico debe ajustarse a ello ${ }^{13}$.

\section{Teoría del Doble Derecho}

Su defensor es Edoardo Piola Caselli que, en 1927, sostuvo que el derecho de autor es un derecho doble. En realidad, cuando se habla de derechos de autor, se está haciendo alusión a un grupo de derechos, unos de naturaleza personal (denominados derechos morales) y otros de naturaleza patrimonial, clasificándose de la siguiente manera:

\subsection{Derechos Morales}

Se refieren a la tutela del bien creado, cuya titularidad corresponde a su autor. Doctrina nacional afirma que, "la expresión "derecho moral" de origen francés, es la más aceptada, tanto en la doctrina como en las legislaciones de casi todos los países, a pesar de quienes prefieren denominarlo "derecho al respeto", "derecho personal" o "derecho de la personalidad del autor", más cuando algunos consideran que hablar de "derecho moral" afirmaría la existencia de otros derechos que no son morales.

Pero la primera denominación, aunque sea como regla de uso general, ha sido la más acogida, sin que la expresión tenga que ver con la moralidad o inmoralidad del autor o su obra, sino con las facultades de orden personal que vinculan al hombre con su creación intelectual.

En los países de tradición jurídica continental está muy arraigado el término "derecho moral" o "derechos morales", aunque España y Portugal han preferido denominar a estas facultades extrapatrimoniales "derechos personales". Los países de tradición germánica utilizan la terminología "derecho de la personalidad del autor" equivalente a "derecho moral".

La Decisión 351 utiliza los términos "derecho moral", "derechos morales" y "derechos de orden moral", mientras el Decreto Legislativo 822 usa indistintamente las expresiones "derechos de orden moral" $\mathrm{y}$ "derechos morales", en todas las

12. PIZARRO DÁVILA, Edmundo. op. cit., p. 34.

13. PIZARRO DAVILA, Edmundo. op. cit., p. 38. 
disposiciones que se refieren a estas facultades del autor (arts. 21 al 29)"14.

Según el art. 22 del D. Leg. 822, Ley sobre el Derecho del Autor, están conformados por los siguientes derechos:

(i) Divulgación, inédito, anonimato y emplear pseudónimo (art. 2315).

(ii) Paternidad (art. 24 ${ }^{16}$ ).

(iii) Integridad (art. 25 $5^{17}$ ).

(iv) Modificación o variación (art. 2618).

(v) Retiro de la obra del comercio (art. $27^{19}$ ).

(vi) Acceso (art. 28 ${ }^{20}$ ).

Características de este derecho son su inalienabilidad, inembargabilidad, imprescriptibilidad, irrenunciabilidad y perpetuidad (art. 2121).
Es inalienable porque "no se puede enajenar el ejercicio de un derecho de la personalidad sin enajenar al mismo tiempo la substancia"22. Es irrenunciable porque la obra, al ser producto intelectual de su mentor, no puede desunirse de éste. Es perpetuo e imprescriptible "como perpetuo e imprescriptible es el respeto debido a la persona humana" 23 .

Problema que se presenta es el de la pretendida transmisibilidad del derecho moral postmortem auctoris, a los herederos. Al respecto, se sostiene que "la perpetuidad del derecho moral, especialmente en lo que atañe a la paternidad del autor y a la integridad de la obra, acogida por la doctrina y algunas legislaciones, no tiene por objeto eternizar un derecho subjetivo en cabeza de sucesivos herederos y

14. ANTEQUERA PARILLI, Ricardo y FERREYROS CASTAÑEDA, Marisol. El nuevo derecho de autor en el Perú, Perú Reporting, Lima, 1996, pp. 110-111.

15. El cual establece que "por el derecho de divulgación, corresponde al autor la facultad de decidir si su obra ha de ser divulgada y en qué forma. En el caso de mantenerse inédita, el autor podrá disponer, por testamento o por otra manifestación escrita de su voluntad, que la obra no sea publicada mientras esté en el dominio privado, sin perjuicio de lo establecido en el Código Civil en lo referente a la divulgación de la correspondencia epistolar y las memorias.

El derecho de autor a disponer que su obra se mantenga en forma anónima o seudónima, no podrá extenderse cuando ésta haya caído en dominio público".

16. Según el cual "el autor tiene el derecho de ser reconocido como tal, determinando que la obra lleve las indicaciones correspondientes y de resolver si la divulgación ha de hacerse con su nombre, bajo seudónimo o signo, o en forma anónima".

17. Por el cual "el autor tiene, incluso frente al adquirente del objeto material que contiene la obra, la facultad de oponerse a toda deformación, modificación, mutilación o alteración de la misma".

18. En el que "el autor antes o después de su divulgación tiene la facultad de modificar su obra respetando los derechos adquiridos por terceros, a quienes deberá previamente indemnizar por los daños y perjuicios que les pudiere ocasionar".

19. A través del cual "el autor tiene el derecho de suspender cualquier forma de utilización de la obra, indemnizando previamente a terceros los daños y perjuicios que pudiere ocasionar.

Si el autor decide reemprender la explotación de la obra, deberá ofrecer preferentemente los correspondientes derechos al anterior titular, en condiciones razonablemente similares a las originales.

El derecho establecido se extingue a la muerte del autor. Una vez caída la obra en el dominio público, podrá ser libremente publicada o divulgada, pero se deberá dejar constancia en este caso que se trata de una obra que el autor había rectificado o repudiado".

20. Por este derecho "el autor tiene la facultad de acceder al ejemplar único o raro de la obra cuando se halle en poder de otro a fin de ejercitar sus demás derechos morales o los patrimoniales reconocidos en la presente ley.

Este derecho no permitirá exigir el desplazamiento de las obras y el acceso a la misma se llevará a efecto en el lugar y forma que ocasionen menos incomodidades al poseedor".

21. Este artículo, en su segunda parte, establece que "a la muerte del autor, los derechos morales serán ejercidos por sus herederos, mientras la obra esté en dominio privado, salvo disposición legal en contrario".

22. VON GIERKE, Otto. Citado por Edmundo PIZARRO DÁVILA, op. cit., p. 59.

23. VON GIERKE, Otto. citado por Edmundo PIZARRO DÁVILA, op. cit. 
generaciones, por tiempo indefinido, sino que tal perpetuidad existe por razones de interés general, de manera que extinguido el derecho patrimonial por el transcurso de un tiempo determinado después de la muerte del autor, de acuerdo a cada legislación, las facultades morales son ejercidas por los órganos o instituciones definidos legislativamente, en nombre de la colectividad y en defensa del patrimonio científico, literario y artístico, evitando el plagio y las deformaciones a la obra, en perjuicio del propio acervo cultural de la comunidad" 24 . En atención a ello, el art. 29 de la ley que comento, establece que:

"En resguardo del patrimonio cultural, el ejercicio de los derechos de paternidad e integridad de las obras que pertenezcan o hayan pasado al dominio público corresponderá indistintamente a los herederos del autor, al Estado, a la entidad de gestión colectiva pertinente o a cualquier persona natural o jurídica que acredite un interés legítimo sobre la obra respectiva".

Doctrina brasileña apunta que:

"Los derechos morales son absolutos, perpetuos, irrenunciables e inalienables, y se constituyen de la paternidad de la obra y su garantía, la defensa del inédito, el arrepentimiento, que prevalece sobre la cesión, la facultad de corrección, el respeto a la obra creada, que no puede ser modificada por terceros, ni ignorada (...). Los derechos patrimoniales son alienables.

Los derechos morales son estudiados generalmente sobre un doble aspecto: en vida del autory después de su muerte, con la desaparición del creador alguien ha de velar por la integridad de la producción, especialmente los herederos, "les gardiens de l'ouvre"IIn25.

\subsection{Derechos Patrimoniales}

Independientemente del ejercicio de los derechos morales del autor, cabe la posibilidad de disponer sobre el producto de la invención, a título gratuito u oneroso. Se observa que el derecho patrimonial "es transferible, temporal y transmisible por herencia. Transferible por cuanto el autor tiene (...) la facultad exclusiva y excluyente de disponer de su obra a cualquier título. Temporal porque su goce está limitado por el tiempo de vida del autor, y después de su muerte por el plazo de amparo que la legislación nacional determina. Consecuentemente, es transmisible por herencia"26. El art. 30 de la Ley de Derechos del Autor, prescribe que:

"El autor goza del derecho exclusivo de explotar la obra bajo cualquier forma o procedimiento, y de obtener por ello beneficios, salvo en los casos de excepción legal expresa".

Estos derechos, según el art. 31, permiten realizar, autorizar o prohibir, lo siguiente:

(i) La reproducción de la obra por cualquier forma o procedimiento.

(ii) La comunicación al público de la obra por cualquier medio.

(iii) La distribución al público de la obra.

(iv) La traducción, adaptación, arreglo u otra transformación de la obra.

(v) La importación al territorio nacional de copias de la obra hechas sin autorización del titular del derecho por cualquier medio incluyendo mediante transmisión.

(vi) Cualquier otra forma de utilización de la obra que no está contemplada en la ley como

24. ANTEQUERA PARILLI, Ricardo. El Derecho de Autor y el Derecho a la Cultura. En: III Congreso Internacional sobre la Protección de los Derechos Intelectuales (Del Autor, el Artista y el Productor), edición patrocinada por la Confederación Internacional de Sociedades de Autores y Compositores (CISAC), la Biblioteca Nacional del Perú y el Consejo Nacional de Ciencia y Tecnología (CONCYTEC), Lima, 1988, p. 30.

25. BASTOS MEIRA, Silvio. O Direito vivo, Editora de Universidad Federal de Goiás, Goiánia, 1984, p. 96.

26. PIZARRO DÁVILA, Edmundo. op. cit., p. 61. 
excepción al derecho patrimonial. Con esta cláusula general, se cubren los eventuales vacíos que se pudiesen presentar.

Mediante Ley 29316, Ley que modifica, incorpora y regula diversas disposiciones a fin de implementar el Acuerdo de Promoción Comercial suscrito entre el Perú y los Estados Unidos de América, del 13.01.09, se incorporó el siguiente párrafo al art. 30 de la Ley de Derechos de Autor:

"El ejercicio de los derechos morales, según lo establecido en la presente norma, no interfiere con la libre transferencia de los derechos patrimoniales".

Coincido plenamente con esta corriente. El error de las anteriores posiciones radicó en observar sólo una de las dos vertientes de este derecho. El hecho de ser autor de la obra creada (y no otros), es de carácter distinto de los beneficios económicos que ésta pueda originar. Ambas situaciones son tuteladas por el Derecho, acorde a estos datos proporcionados por la experiencia social.

Se sostiene que el derecho moral de autor no debería ser considerado dentro de los derechos de la persona, por cuanto, mientras que, para estos últimos la tutela del ordenamiento ha sido modelada con referencia a atributos de la persona, vale decir, a hechos o eventos referentes a la persona misma, en el caso del derecho moral, la tutela aflora y se consolida exclusivamente en virtud de una relación que liga genéticamente la persona a un opus, a un producto, a una objetividad materializada ${ }^{27}$. En efecto, el objeto del derecho moral es la obra en cuanto tal, como entidad objetivizada y exteriorizada, aunque no sea publicada (es el caso de la obra inédita), no porque sea reflejo de la personalidad del autor, sino, en línea general, porque por éste la obra es creada e insertada establemente en el mundo sensible: es por ello que todo juicio sobre la obra se refleja sobre el autor, sobre su personalidad ${ }^{28}$.

\section{LOS DERECHOS DEL AUTOR EN LA LEGISLACIÓN PERUANA}

En la Constitución expedida por San Martín, se consagra "la inviolabilidad de las propiedades intelectuales". Posteriormente, también se hace mención en la Constitución de 1860, en su artículo 26 , el que prescribe la inviolabilidad de las propiedades, pero desde un punto de vista generalizado. Igualmente, consagran estos derechos las Constituciones de 1920 y 1933, estableciendo esta última la garantía y protección del Estado sobre los derechos de los autores e inventores al prescribir en su artículo 30 que "El Estado garantiza y protege los derechos de autores e inventores. La ley regirá su ejercicio". En cumplimiento con el numeral 30 de la Constitución de 1933, el gobierno de Prado promulgó en 1961 la Ley 13714 sobre los derechos de los autores e inventores.

Al año siguiente, la Junta Militar de Gobierno aprobó el reglamento de esta ley mediante D.S. 61. Tanto la ley como el reglamento han sido derogados por el D. Leg. 822, Ley sobre Derecho de Autor, del 23.04.96.

El Código Civil de 1984 regula, en su artículo 18, los derechos del autor, estableciendo, de manera general, su protección acorde con una ley especial. Debido a la amplitud de este numeral quedan comprendidos, tanto los derechos morales o personales del autor como los patrimoniales. Sin embargo, esta norma debe ser entendida como remisiva y referente (sólo) a los denominados derechos morales del autor, ya que éstos forman parte de los derechos de las personas.

\section{LOS DERECHOS DE AUTOR EN LA EXPERIENCIA JURISPRUDENCIAL ADMINISTRATIVA NACIONAL}

La Corte Suprema de los Estados Unidos en 1991, en la decisión Feist vs. Rural Telephone,

27. SANTORO, Emanuele. Onore e reputazione nell'art. 20 della legge sul diritto d'autore. En: La informazione e i diritti della persona, a cura de Guido ALPA, Mario BESSONE, Luca BONESCHI y Giandomenico CAIAZZA, Centro di iniziativa giuridica Piero Calamandrei, Jovene, Napoli, 1983, p. 75.

28. SANTORO, op. cit., p. 80. 
sentenció que las páginas blancas de una guía telefónica ordenada alfabéticamente carecen de la creatividad que constitucionalmente se requiere para considerarse como un trabajo digno de copyright ${ }^{29}$. El "formante" jurisprudencial administrativo nacional siguió este criterio con las Resoluciones Jefaturales No. 149-ODA-INDECOPI, No. 150-ODA-INDECOPI y No. 151-ODAINDECOPI, del 18.08.94, en las cuales se denegó el registro en la Oficina de Derechos de Autor a la Compañía Peruana de Teléfonos de la "Guía Clasificada 1994 (páginas amarillas)", la "Guía de Oro 1994" y la "Guía Alfabética 1994 (páginas blancas)", por cuanto carecían de originalidad ${ }^{30}$.

Es en este sentido que también se dirige el "formante" legislativo nacional, cuando en el artículo 2.1. del D. Leg. 822, del 23.04.96, Ley sobre el Derecho de Autor, define al autor como la "persona natural que realiza la creación intelectual". El art. 5, inc. n, considera como obra protegida a"toda producción del intelecto en el dominio literario o artístico, que tenga características de originalidad y sea susceptible de ser divulgada o reproducida por cualquier medio o procedimiento, conocido o por conocerse" (el subrayado es mío). El Tribunal de Defensa de la Competencia y de la Propiedad Intelectual, en su Resolución No. 1349-2001-/TPI-INDECOPI, del 03.10.01, precisó que:

"La originalidad de la obra reside en la expresión -en forma representativa-creativa e individualizada de la obra, por mínimas que sean la creación y esa individualidad. No se requiere que la obra sea novedosa en sentido objetivo.

Si bien toda obra es el producto del esfuerzo de su creador, no todo lo producido con esfuerzo merece protección por derechos de autor. Ello sólo será posible en la medida que la creación tenga elementos de originalidad suficientes para ser considerada como obra. Admitir lo contrario, implicaría proteger incluso aquello que no es objeto de protección por derechos de autor, como la elaboración de la lista de películas que se exhiben en los cines de Lima.

El requisito de originalidad o individualidad implica que para la creación de la obra debe existir un espacio para el desarrollo de la personalidad de su autor. En consecuencia, lo que ya forma parte del patrimonio cultural - artístico, científico o literario - no puede ser individual. Igualmente, la originalidad sirve para diferenciar las obras protegidas por derechos de autor de las banales, de la vida diaria, rutinarias. Tampoco puede decirse que una creación es original si la forma de expresión se deriva de la naturaleza de las cosas o es una mera aplicación mecánica de lo dispuesto en algunas normas jurídicas o por lógica o si la forma de expresión se reduce a una simple técnica que sólo requiere de la habilidad manual para su ejecución. Sin embargo, de acuerdo a las circunstancias de un caso particular, un pequeño grado de creatividad intelectual puede ser suficiente para determinar que la obra sea original o individual.

Así, en la lista enunciada de manera ejemplificativa en el artículo 4 de la Decisión 351 concordado con el artículo 5 del Decreto Legislativo 822 de las obras que merecen una protección por derechos de autor, la originalidad constituye un filtro para la concesión de la protección en el caso en concreto.

Pero el requisito de originalidad o individualidad no sólo sirve para determinar qué

29. GOLDSTEIN, Paul. Copyright and author's right in the twenty-first century, en Wipo Worldwide Symposium on the Future of Copyright and Neighboring Rigths, 1994, p. 262.

30. Cabe añadir que habiéndose presentado una nueva prueba instrumental y alegándose que el registro solicitado comprendía además otros elementos creativos, tales como diseño de carátula, dibujos, mensajes, etc., se decidió, mediante las Resoluciones Jefaturales No. 209-94-DA-INDECOPI, No. 210-94-DA-INDECOPI y No. 211-94-DA-INDECOPI, del 17.10.94, registrar las guías bajo comentario en el Registro Nacional de Derechos de Autor, precisando que "Ia protección que otorga la legislación de derecho de autor no abarca la ordenación alfabética de usuarios que contiene el ejemplar objeto del registro indicado". 
cosa es una obra y qué no, sino también para determinar el alcance de la protección del derecho de autor. Sólo se protege contra plagio aquélla parte de la obra que refleje la individualidad del autor.

Ahora bien, la determinación de si una obra es original constituye una cuestión de hecho. Se trata además de una noción subjetiva, en la medida que la originalidad no puede apreciarse de la misma manera en todas las obras. En ese orden de ideas, para el derecho de autor el término creación no tiene el significado corriente de sacar algo de la nada y la originalidad de la obra no tiene que ser absoluta, por lo tanto no es necesario que la inspiración del autor esté libre de toda influencia ajena" (el subrayado es mío).

¿Las sumillas, concordancias, jurisprudencia anexa y notas a pie de página de un código (civil, por ejemplo) tienen el requisito de la originalidad? Para la Oficina de Derechos de Autor del INDECOPI sólo tienen el requisito de originalidad las notas al pié de página. Así, mediante Resolución No. 042-2001/ODA-INDECOPI, del 23.02.01, en la cual se establece que:

"Diferente ocurre en el caso de las notas al pie de página, las mismas que ilustran sobre datos o hechos relacionados indirectamente con el tema principal $y$, en el presente caso, indican la existencia de alguna otra norma jurídica que sustituya, inaplique o colisione con el artículo anotado".

Para el Tribunal de Defensa de la Competencia y de la Propiedad Intelectual, en su Resolución No. 543-2002-/TPI-INDECOPI, del 10.06.02, precisó que los resúmenes de las sentencias judiciales, así como las notas a pie de página tipo comentario sí merecen la protección del derecho de autor. Así, a propósito de la jurisprudencia se hace la siguiente distinción:

"De acuerdo a una de las acepciones del término jurisprudencia, éste alude al conjunto de pronunciamientos de carácter jurisdiccional dictados por órganos judiciales y administrativos. Estos pronunciamientos constituyen el llamado Derecho judicial en cuanto comprende a los fallos y sentencias emanados de los jueces y tribunales judiciales, o bien el denominado Derecho jurisprudencial administrativo, en cuanto involucra a las resoluciones finales de los tribunales administrativos.

El artículo 9 del Decreto Legislativo 822, señala que no están protegidos por el derecho de autor los textos oficiales de carácter legislativo, administrativo o judicial, ni las traducciones oficiales de los mismos, sin perjuicio de la obligación de respetar los textos y citar la fuente.

(...) Si bien la jurisprudencia no es protegible por el derecho de autor, tal como se indicó anteriormente, sílo puede ser una base de datos que contenga este tipo de información siempreque sea original, como también puede ser protegido un resumen de dichajurisprudencia, puesto que en este último caso existe un esfuerzo creativo de autor para sintetizar en un breve texto lo que expresó una sentencia.

(...) La Sala reconoce el esfuerzo invertido por el denunciante en la búsqueda y recolección de la jurisprudencia que el denunciante presenta en su publicación; sin embargo, tal como se indicó en el numeral 6 de la presente resolución, no todo lo producido con esfuerzo es protegible por el derecho de autor, ya que ello sólo ocurrirá cuando se esté ante una creación con rasgos de originalidad.

La denunciante alega que los extractos de jurisprudencia que aparecen en su obra merecen protección por el derecho de autor; sin embargo, la Sala advierte que la gran mayoría constituyen citas de extractos de resoluciones judiciales, las cuales no pueden ser protegidas, ya que se trata de la reproducción de textos no protegidos por el derecho de autor.

No obstante lo anterior, la Sala advierte que existen algunos casos en los que el texto jurisprudencial que se presenta corresponde a un resumen de la sentencia y no a una simple cita de la misma (...) 
La Sala determina que los resúmenes de sentencias judiciales, (...), no constituyen un simple parafraseo del texto de la sentencia sino que presentan de una forma particular la idea que surge del texto de la sentencia, por lo que presenta una forma de expresión que merece ser protegida por el derecho de autor".

Con respecto a las notas al pie de página, se establece que, en alguna de ellas:

"la Sala es de la opinión que si bien hacen referencia a sentencia y a modificatorias legales, éstas van acompañadas de breves comentarios, cuya forma de expresión presenta un mínimo grado de originalidad, que los hace merecedores de protección por el derecho de autor.

Cabe precisar que lo que se protege es la forma de expresión utilizada no la información contenida en el pie de página, es por ello que cualquier persona puede emplear dicha información siempre y cuando utilice para tal efecto una forma de expresión distinta".

Otro caso: Herbert Morote interpuso una denuncia ante la Oficina de Derechos de Autor del INDECOPI (ahora Comisión de Derecho de Autor) contra el señor Alfredo Bryce Echenique por presunta infracción a sus derechos morales de paternidad, divulgación e integridad y patrimoniales de reproducción y distribución respecto de una obra (que después amplió a otras obras de autores diversos), que fue declarada infundada, mediante Resolución No. 0323-2007/ODA-INDECOPI, del 12.12.07, por insuficiencia de pruebas. Dicha Resolución fue confirmada por la Sala de Propiedad Intelectual del Tribunal del INDECOPI mediante Resolución No. 1121-2008/TPI-INDECOPI del 13.05.08. Dado que la Oficina de Derechos de Autor había tomado conocimiento de la posible comisión de plagio por parte del señor Bryce Echenique en perjuicio de diversos autores, a raíz de la denuncia del señor Morote, el 14.11.007, la Oficina de Derechos de Autor del INDECOPI (actualmente Comisión de Derecho de Autor), inició una denuncia de oficio contra el señor Alfredo Bryce Echenique, por supuesta infracción a los de- rechos morales de paternidad e integridad, y patrimonial de reproducción, establecidos en los artículos 24, 25 y 32 del Decreto Legislativo 822, Ley sobre el Derecho de Autor, de los autores de las obras literarias "Potencias sin poder" (Oswaldo de Rivero), "Uso social del tabaco" (Eulalia Solé), "El declive del poder estadounidense" (Graham Füller), "Las esquinas habitadas" (José María Pérez Álvarez), "La leyenda de John Lennon genera cerca de 19 millones de euros al año" (Nacho Para) y "Londres busca detectives" (Carlos Sentís) en la modalidad de plagio. El 13.05.08, el señor Herbert Briand Morote Barrionuevo puso en conocimiento de la Oficina de Derechos de Autor la existencia de veinte presuntas nuevas infracciones a los derechos morales de paternidad e integridad, y patrimonial de reproducción, de distintos autores por parte del denunciado Alfredo Bryce Echenique, de acuerdo a una investigación realizada por la doctora María Soledad de la Cerda. El 04.07.08, la Oficina de Derechos de Autor, luego de una revisión de los medios probatorios presentados por el señor Herbert Briand Morote Barrionuevo, considerando lo dispuesto en el artículo 105 de la Ley del Procedimiento Administrativo General, Ley 27444, dispuso iniciar de oficio una denuncia administrativa contra Alfredo Bryce Echenique, por supuesta infracción a los derechos morales de paternidad e integridad, y patrimonial de reproducción, establecidos en los artículos 24, 25 y 32 del Decreto Legislativo 822, de los autores de las obras literarias "América Latina: ¿regresando al pasado para enfrentar el futuro?" (Jordi Urgell), "La estupidez perjudica gravemente la salud" (Jordi Cebría Andreu y Victor Cabré Segarra), "Estrellas Médicas" (Sergi Pámies), "Contra las fotos de ataúdes con soldado dentro" (Josep Pernau), "La angustia de Kafka" (Juan Carlos Ponce), "John Steinbeck, un novelista de los oprimidos" (Juan Carlos Ponce), "John Ford, la épica del Western" (Blas Gil Extremera) ,"William Blake y los proverbios del Infierno" (Jorge De La Paz) , "El psicoanálisis en el cine de Woody Allen" (Benjamín Herreros Ruiz Valdepeñas) ,"1905, el año Maravilloso" (Victoria Toro) , "Cultura y Civilizaciones" (Cristóbal Pera), "La enfermedad de la Nostalgia" (Luis M. Iruela) , "La correspondencia entre Pound y Joyce" (Odile Baron Supervielle) , "La Nueva amenaza nuclear" (Oswaldo de

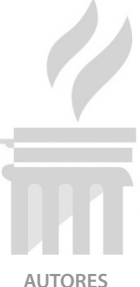
NACIONALES

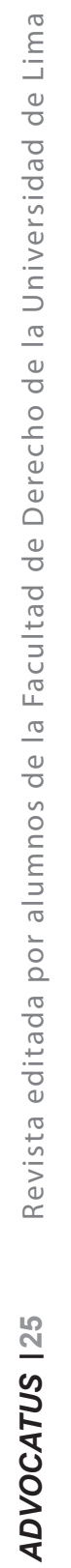


Rivero), "Ségolène, de corazón" (Francesc-Marc Alvaro), “Cómo combatir el terrorismo?" (Joseph María Puigjaner), "Cuerpos distorsionados y desfigurados: lo grotesco y lo freak en la cultura actual" (Cristóbal Pera), en la modalidad de plagio. Asimismo, ordenó la acumulación del procedimiento seguido en el expediente No. 008292008/ODA al que se sigue en el expediente No. 001573-2007/ODA. El denunciado interpuso las excepciones de falta de legitimidad para obrar y de incompetencia. Mediante Resolución No. 0142/2008-CDA-INDECOPI, del 24.12.08, se consideró que:

"Se lesiona el derecho de paternidad cuando una persona no reconoce la paternidad de una obra correspondiente al autor; y también se presenta cuando, sin ser el autor de una obra se atribuye la autoría de ésta, sea en forma parcial o total.

Esta última conducta, se conoce también en la doctrina como plagio, el cual puede presentarse bajo dos formas:

- Plagio servil

- Plagio inteligente.

En cuanto al plagio servil, el autor Horacio Fernández Depech señala:

"Es presentar como de su propia autoría una obra ajena, a la que se le ha copiado y cambiado solamente el título y nombre del autor, sin alterar su contenido (...) $)^{1 / 31}$.

El plagio inteligente consiste en pretender hacer aparecer como una nueva obra la obra plagiada mediante ligeras variaciones.

En el caso de plagio, la obra que nace como producto de éste, no tiene ningún esfuerzo creativo. Así, en una sentencia de la Sala $1^{a}$ del Tribunal Supremo de España emitida el 28 de enero de 1995, se define el plagio de la siguiente manera:
"Por plagio hay que entender, en su acepción más simplista, todo aquello que supone copiar obras ajenas en lo sustancial. Se presenta más bien como una actividad material mecanizada y muy poco intelectual y menos creativa, carente de toda originalidad y de concurrencia de ingenio o talento humano, aunque aporte alguna manifestación de ingenio (...). Las situaciones que representan plagio hay que entenderlas como las de identidad, así como las encubiertas, pero que descubren al despojarlas de los ardides y ropaje que las disfrazan, su total similitud con la obra original, produciendo un estado de apropiación y aprovechamiento de la labor creativa y esfuerzo ideario o intelectivo ajeno..."

En el presente procedimiento, a efecto de determinar si el denunciado Alfredo Bryce Echenique ha infringido el derecho de autor correspondiente a distintos autores, la Comisión considera pertinente analizar los medios probatorios que obran en el expediente respecto de cada una de las obras materia del presente procedimiento".

De la comparación de lo escrito por Bryce Echenique y los presuntos plagiados, se decide:

"PRIMERO.- DECLARAR INFUNDADA la excepción de incompetencia planteada por el denunciado.

SEGUNDO.- DECLARAR INFUNDADA la excepción de falta de legitimidad para obrar planteada por el denunciado.

TERCERO.- DECLARAR FUNDADA en parte la excepción de prescripción planteada por el denunciado únicamente respecto de una presunta infracción al derecho de reproducción del autor Graham Fuller e INFUNDADA la excepción de prescripción respecto de una presunta infracción a sus derechos morales de paternidad e inte-

31. FERNÁNDEZ DELPECH, Horacio. Protección Jurídica del Software; Edit. Abeledo-Perrot; Buenos Aires; $1^{a}$ ed.; pp. 4748. 
gridad sobre la obra "El declive del poder estadounidense".

CUARTO.- DECLARAR FUNDADA LA DENUNCIA iniciada de oficio contra ALFREDO BRYCE ECHENIQUE por infracción a los derechos morales de paternidad e integridad, $y$ patrimonial de reproducción, de los autores Oswaldo de Rivero, Eulalia Solé, Nacho Para, Carlos Sentís, Jordi Cebrià Andreu, Víctor Cabré Segarra, Sergi Pàmies, Juan Carlos Ponce, Blas Gil Extremera, Jorge de la Paz, Benjamín Herreros Ruiz Valdepeñas, Cristóbal Pera, Luis M. Iruela, Frances-Marc Alvaro, Joseph María Puigjaner, en consecuencia, sancionar al denunciado ALFREDO BRYCE ECHENIQUE con una MULTA ascendente a CINCUENTA UNIDADES IMPOSITIVAS TRIBUTARIAS (50 U.I.T.), la misma que deberá ser cancelada dentro del plazo de cinco (05) días, contados a partir del día siguiente de notificada la presente Resolución, bajo apercibimiento de remitirse a cobranza coactiva ${ }^{32}$.

QUINTO.- ARCHIVAR el presente procedimiento respecto de una presunta infracción a los derechos de autor de Graham Fuller ("El declive del poder estadounidense"), José María Pérez Álvarez ("Las esquinas habitadas"), Jordi Urgell ("América Latina: iregresando del pasado para enfrentar el futuro?"), Joseph 'Pernau ("Contra las fotos de ataúdes con soldado dentro"), Victoria Toro ("1905, el año maravilloso"), Odile Baron Supervielle ("La correspondencia entre Pound y Joyce") y Cristóbal Pera ("Cuerpos distorsionados y desfigurados: lo grotesco y lo freak en la cultura actual"), por las razones expuestas en la parte considerativa de la presente Resolución.

SEXTO.- ORDENAR la inscripción de la presente resolución en el Registro de Infractores a la Legislación sobre el Derecho de Autor.

SÉPTIMO.- Póngase en conocimiento del
Ministerio Público la presente Resolución para los fines pertinentes".

En segunda instancia, mediante Resolución No. 2683-2009/TPI-INDECOPI, del 16.10.09, se decidió:

"Primero.- CONFIRMAR la Resolución No 1422008/CDA-INDECOPI de fecha 24 de diciembre de 2008, emitida por la Comisión de Derecho de Autor en el extremo que declaró FUNDADA la denuncia iniciada de oficio contra Alfredo Bryce Echenique por infracción a los derechos morales de paternidad e integridad, y patrimonial de reproducción, de los autores:

- Oswaldo de Rivero

- Eulalia Solé

- Nacho Para

- Carlos Sentis

- Jordi Cebrià Andreu

- Víctor Cabré Segarra

- Sergi Pàmies

- Juan Carlos Ponce

- Blas Gil Extremera

- Jorge de la Paz

- Benjamín Herreros Ruiz Valdepeñas

- Cristóbal Pera

- Luis M. Iruela

- Frances-Marc Alvaro

- Joseph Maria Puigjaner

Segundo.- CONFIRMAR la Resolución No 142-2008/CDA-INDECOPI de fecha 24 de diciembre de 2008, emitida por la Comisión de Derecho de Autor, en el extremo que dispuso imponer la sanción de multa a Alfredo Bryce Echenique, la cual se modifica de 50 UIT a 20 UIT; así como en el extremo que dispuso ordenar la inscripción de la resolución en cuestión en el Registro de Infractores a la Legislación sobre el Derecho de Autor.

Tercero.- Dejar FIRME la Resolución No 142-2008/CDA-INDECOPI de fecha 24 de di-

32. Según lo señala el artículo 37 del decreto legislativo 807 el cual señala: "la sanción de multa aplicable será rebajada en un veinticinco por ciento (25\%) cuando el infractor cancele el monto de la misma con anterioridad a la culminación del término para impugnar la resolución que puso fin a la instancia, en cuanto no interponga recurso impugnativo alguno contra dicha resolución", 
ciembre de 2008, emitida por la Comisión de Derecho de Autor en lo demás que contiene".

Se interpuso la nulidad de esta decisión. Mediante Resolución No. 3132-2009/TPI-INDECOPI, del 23.11.09, se denegó dicha solicitud y se amplió la Resolución No. 2683-2009/TPIINDECOPI, en los siguientes términos:

"En su apelación, Alfredo Bryce Echenique ha mencionado su disconformidad con lo dispuesto en el numeral séptimo de la parte resolutiva de la Resolución No 142-2008/CDAINDECOPI que dispuso poner en conocimiento del Ministerio Público dicha resolución para los fines pertinentes.

El artículo 185 del Decreto Legislativo 822, establece que "Cuando los hechos materia del procedimiento administrativo constituyan presunto delito, la Oficina de Derechos de Autor podrá formular denuncia penal ante el Ministerio Público (...)".

El Código Penal establece en su artículo 219 lo siguiente:

\section{"Artículo 219.- Plagio}

Será reprimido con pena privativa de libertad no menor de cuatro ni mayor de ocho años y noventa a ciento ochenta días multa, el que con respecto a una obra, la difunda como propia, en todo o en parte, copiándola o reproduciéndola textualmente, o tratando de disimular la copia mediante ciertas alteraciones, atribuyéndose o atribuyendo a otro, la autoría o titularidad ajena".

En el presente caso, se ha determinado que Alfredo Bryce Echenique ha cometido plagio respecto de textos de diversos autores. En tal sentido, siguiendo lo establecido en casos similares $^{33}$, corresponde confirmar la disposición de poner en conocimiento del Ministerio Público la Resolución No. 142-2008/CDA-INDECOPI e incluso la Resolución No. 2683-20009/TPIINDECOPI y la presente, para que, de acuerdo a sus atribuciones $y$, de ser el caso, determine la posibilidad de la interposición de una denuncia penal por plagio contra Alfredo Bryce Echenique.

Por ello, se confirmó la Resolución No. 142-2008/ CDA-INDECOPI en el extremo que dispuso poner en conocimiento del Ministerio Público la resolución en cuestión.

\section{UN CASO INSÓLITO: EL PLAGIO EN UNA SENTENCIA}

Es de lamentable conocimiento público el contrato de venta de línea editorial que hicieron, por un lado, los Crousillat en representación de América Televisión (Canal 4) y por otro, Vladimiro Montesinos en representación del Estado, el cual, según la sentencia de la Segunda Sala Penal Especial de la Corte Superior de Justicia de Lima, del 08.08.06, fue redactado en los siguientes términos:

"Se tiene en autos, que de fojas doce mil setecientos cuarenticinco a doce mil setecientos cuarentisiete aparece en copia simple un documento intitulado "contrato de Locación de Servicios", del siete de noviembre de mil novecientos noventinueve, suscrito entre José Francisco Crousillat Carreño quien interviene como supuesto "Gerente General" del Canal cuatro-América Televisión (entiéndase Compañía Peruana de Radiodifusión - Canal cuatro) y de la otra parte "el contratante" que no consigna sus datos de identidad, argumentando razones estrictamente de confidencialidad, pero que se trataba de Vladimiro Montesinos Torres, apreciándose que las obligaciones contenidas en dicho documento eran; de un lado, por parte de "El contratante" entregar mensualmente a "El Canal" la suma de un millón y medio de dólares americanos, precisando que dicho contrato debía ejecutarse entre el siete de noviembre de mil novecientos noventinueve y el nueve de abril de dos mil.

(...) Las obligaciones asumidas por "El Canal" en virtud a dicho contrato eran: "a) no admitir

33. Ver Resoluciones No. 1460-2009/TPI-INDECOPI y No. 2720-2008/TPI-INDECOPI. 
nipasar ninguna propaganda política directa o indirectamente a menos que sea dispuesta por "El Contratante" b) No pasar avisos políticos de ninguna índole de los candidatos a la Presidencia de la República, al Congreso de la República o a cualquier cargo público en la Campaña electoral para el año dos mil, a menos que "El Contratante" lo solicite explícitamente; c) No promover directa o indirectamente la imagen de ninguna agrupación política, partido o movimiento político ni de sus dirigentes o representantes sin la aprobación por escrito de "El Contratante" d) no hacer ni pasar entrevistas, debate ni reportajes a candidatos a la Presidencia y/o al Congreso de la República sin la aprobación escrita de "El Contratante" e) No emitirningún otro programa con contenidos que refieran explícita o implícitamente a temas políticos sin que éstos sean aceptados y/o aprobados por "El Contratante" $f$ ) Propalar noticieros en sus horarios habituales de lunes a sábados y sacar al aire un programa político los días domingos en el horario de las veinte horas, empezando la primera quincena del mes de enero del año dos mil, cuyo contenido y titulares serán coordinados y aprobados por "El Contratante" g) Revisar diariamente con "El Contratante" el contenido de todos los titulares y todos los programas noticiosos antes de que estos sean propalados a nivel nacional, debiendo incorporar las observaciones que "El Contratante" considere necesarias así como incluir los temas que éste decida en dichos noticieros; $h$ ) Durante cada emisión el Programa "Laura en América", "El Contratante" dispondrá del tiempo que sea necesario para desarrollar los contenidos que estime conveniente; i) Responder por las declaraciones que emita su personal a través de otros medios informativos, televisivos o radiales que no sigan los lineamientos del presente Contrato; j) Reunirse con "El Contratante" las veces que sean necesarias a efecto de hacer las coordinaciones pertinentes para el mejor cumplimiento de lo establecido en el presente contrato."

(...) Por su parte "El Contratante" se comprometía a: "a) cumplir puntualmente con el pago de las mensualidades acordadas; b) coordinar oportunamente con "El Canal" la revisión de los programas noticiosos y el Programa político dominical y c) Realizar las demás acciones que sean menester, acordando además que como garantía del cumplimiento de sus obligaciones, "El Canal" firmará una letra de cambio al portador por el monto que mensualmente recibe y luego de transcurrido dicho término, esta sería incinerada y renovada por un nuevo título valor en las mismas condiciones hasta la conclusión del contrato; de igual modo se pactaron penalidades por incumplimiento.

(...) Finalmente se pactó que: "El Contratante" podrá ejercer durante la vigencia (del contrato) el derecho de veto sobre la participación de cualquier comentarista o periodista de "El Canal", declarando haber suscrito dicho contrato en un solo ejemplar que quedó en manos de "El Contratante"."

Este es un claro ejemplo de un acto jurídico nulo por perseguir un fin ilícito... sin embargo, en su momento, produjo efectos jurídicos, aunque precarios. Así, en la sentencia bajo comentario, se condena a José Enrique Crousillat López Torres como cómplice primario del delito contra la Administración Pública-peculado por apropiación (art. 387 C.P.) en agravio del Estado, tres años de inhabilitación y una indemnización a favor del Estado ascendente a S/.80'000,000.00, "debiendo devolver lo irregularmente obtenido, debiendo precisarse dicho monto en vía de ejecución". Asimismo, por mayoría, se dispuso que la Compañía Peruana de Radiodifusión S.A.Canal Cuatro sea tercero civilmente responsable de los Crousillat y, por lo tanto, solidariamente responsable. La fundamentación es la siguiente:

"85.Ahora bien, corresponde indicar que la comisión de un hecho delictivo, por un lado, da lugar a la responsabilidad penal pero también, en cuanto Acto llícito que produce daño a Terceros a una Responsabilidad Civil, conocida como responsabilidad civil ex delicto. El tercero civilmente responsable resulta ser aquel sujeto procesal, persona natural o jurídica, que sin haber participado en la comisión del delito y sin alcanzarle responsabilidad penal, asume el pasivo civil quedando,

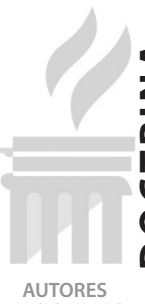


por disposición de la ley, solidariamente obligado con el o los responsables penales, por el importe de la Reparación Civil.

86. Este tipo de responsabilidad se rige por la Teoría de la Responsabilidad Civil, específicamente la Responsabilidad Civil Extracontractual, debiendo acotar que ésta responsabilidad supone la violación del deber general de no causar daño a otro.

87. A fin de aclarar un poco más el panorama respecto a la responsabilidad civil debemos referirnos en primer término a las funciones de la responsabilidad civil, que según la doctrina mayoritaria son: a) reaccionar contra el acto ilícito dañino, a fin de resarcir a los sujetos a los cuales el daño ha sido causado; b) retornar al statu quo ante en el cual la víctima se encontraba antes de sufrir el perjuicio; c) reafirmar el poder sancionatorio del Estado; d) disuadir a cualquiera que intente, voluntaria o culposamente, cometer actos perjudiciales para terceros; y modernamente se han incluido e) la distribución de las pérdidas y f) la asignación de costos, desde una perspectiva de análisis económico del Derecho.

88. Asimismo, debemos indicar que la responsabilidad civil posee elementos constitutivos, comunes tanto a la responsabilidad civil contractual como a la extracontractual, a saber: a) la imputabilidad, es decir, la aptitud del sujeto de derecho de ser responsable por los daños que ocasiona, b) la ilicitud o antijuricidad, es decir, la constatación de que el daño causado no está permitido por el ordenamiento jurídico; c) el factor de atribución, o sea, el supuesto justificante de la atribución de responsabilidad al sujeto, es decir, es el fundamento del deber de indemnizar; d) el nexo causal, concebido como la vinculación entre el evento lesivo y el daño producido; $y$ d) el daño, que comprende las consecuencias negativas derivadas de la lesión de un bien jurídico tutelado.

89. Ahora bien, en función del Factor de Atribución, cabe señalar que existen factores de atribución subjetivos (culpa y dolo) y objetivos (realizar actividades o ser titular de determinadas situaciones jurídicas que la ley considera objetivamente o prescindiendo del criterio de la culpa), a lo que algunos añaden al abuso de derecho y la equidad, pero no hay uniformidad sobre ello.

90. En el caso de la responsabilidad civil derivada de la comisión de un delito, ubicada dentro de la responsabilidad Civil Extracontractual, cabe señalar que nos encontramos frente a la denominada Responsabilidad Objetiva, es decir aquella que se basa en factores de atribución objetivos, considerados como tales por el ordenamiento jurídico. Debiendo indicar que en la sección sexta del Código Civil en el artículo mil novecientos ochenta y uno, se prevé la inclusión de un Tercero como Civilmente Responsable en un proceso penal, cuando se establece que "aquel que tenga a otro bajo sus órdenes, responde por el daño causado por éste último, sí ese daño se realizó en el ejercicio del cargo o en cumplimiento del servicio respectivo" siendo el criterio de imputación, la relación que existe entre el responsable y el sujeto que ha causado el daño, pues desde esta óptica el principal estaría en la obligación de resarcir, por cuanto si se beneficia económicamente con la actividad realizada por el "tercero", debe asumir los costos que origine los daños del mismo (criterio del riesgo-beneficio).

91. Esta responsabilidad no se funda en una responsabilidad puramente vicarial, en la que sí el subordinado no es responsable (subjetivo) entonces no habrá responsabilidad (objetiva) del principal, pues existen casos en los que aun cuando la responsabilidad del subordinado, no se acredita, igualmente responde el principal, ello por que su fundamento radica en la actividad misma de la empresa o del principal y no por una garantía frente a los actos de los subordinados. La responsabilidad del principal no es vicaria ni indirecta, es directa por su propia actividad.

92. Para que se configure esta responsabilidad deben darse los siguientes requisitos: a) una relación de subordinación, debiendo indicarse que lo que cuenta no es tanto la calificación formal que las partes dan a la relación, sino la valoración de la existencia efectiva de una relación sobre la cual una persona actúa a 
pedido, por cuenta o en interés de otro, quien por ser titular de la actividad, a cuya instancia se ha verificado el hecho ilícito, es el sujeto que está en situación de controlar las condiciones del riesgo inherente a esa actividad; $b$ ) que el subordinado ocasione daños, siendo uno de los supuestos de la responsabilidad civil (objetiva) del principal que el dependiente incurra en responsabilidad subjetiva (a título de dolo o culpa), no descartándose, como se dijo antes que hayan casos de responsabilidad objetiva por parte del dependiente, y c) que exista una relación de causalidad o de ocasionalidad necesaria entre el ejercicio de las funciones y el daño. Debiendo recalcar una vez más que en este caso la responsabilidad del tercero civilmente responsable o principal no es a título subjetivo sino objetivo, vale decir que si se verifica la concurrencia de los elementos que la ley señala, entonces aparece la responsabilidad civil.

93. Ahora bien, es pertinente referirnos a los argumentos de descargo enarbolados por la defensa del tercero civilmente responsable, quien sostiene que el "contrato de locación de servicios" tantas veces aludido no es válido desde el punto de vista legal ni estatutario, con lo cual este colegiado está de acuerdo, pero reitera que ello no se ventila en esta causa, pues aquí la imputación en su contra es que un dependiente suyo causó un perjuicio al agraviado (el Estado) en ejercicio de dicha relación de dependencia.

93.1.Es pertinente acotar al respecto que a criterio de éste Colegiado, no es atendible el argumento de que si alguien que tenía en la realidad una relación de dependencia funcional con la empresa, causa un daño, ésta no es responsable porque no se cumplió una formalidad exigida por ley en los actos que realizó o en los acuerdos que concertó, porque ello configuraría un abuso de derecho, mas aun si reconocemos que el Derecho Penal actúa como una forma extrema de control social cuando otras formas de control han fracasado.

94.Otro asunto al que nos queremos referir es al supuesto no ingreso de dichos caudales estatales recibidos por José Enrique Crousillat
López Torres y por José Francisco Crousillat Carreño a la contabilidad de la empresa, lo que resulta siendo en la realidad una exigencia poco razonable, por decir lo menos, pues si bien probablemente sea imposible encontrar un registro en el Libro Mayor de la empresa que señale el origen de dinero proveniente del Estado entregado para poner a disposición del gobierno la línea editorial del canal, esto según lo aseveró el propio José Enrique Crousillat López Torres, al ser preguntado respecto a ¿sí parte del dinero entregado por Vladimiro Montesinos Torres ingresó a las cuentas de Compañía Peruana de Radiodifusión S.A. Canal Cuatro? Indicó: "tengo entendido que si, no me consta pero tengo entendido que si", precisando posteriormente que esto se lo mencionó su hijo José Francisco Crousillat Carreño.

94.1. Pero ello no es lo único que nos permite razonar así, sino que el propio "peritaje de parte" presentado por el Tercero Civilmente Responsable, señala que la situación económica de la empresa era bastante mala, textualmente señala:

94.2. "3.9. Situación Financiera. Ubicándonos en el periodo objeto de nuestro trabajo pericial, vemos que la compañía, como todas las empresas en el ámbito nacional, desarrolla sus actividades en un entorno recesivo, habiendo experimentado pérdidas significativas durante los años 1998 y 1999, llegando al año 2000 con un patrimonio negativo de S/. 65'514,000.00 configurándose de esta manera la obligatoriedad de la reducción del capital social por pérdidas, que ordena el art. $N^{\circ} 220$ de la Nueva Ley General de Sociedades, que dispone que la reducción del capital, tiene carácter obligatorio, cuando las pérdidas hayan disminuido el capital social en más del $50 \%$ y hubiese transcurrido un ejercicio sin haber sido superado, salvo que se cuente con reservas legales o de libre disposición, se realicen nuevos aportes o los accionistas asuman la pérdida, en la cuantía que compense el desmedro.

94.3. La Compañía igualmente muestra un alto endeudamiento (un pasivo total

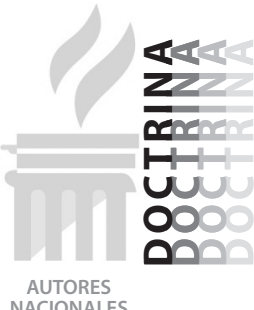
AUTORES
NACIONALES 
de S/. 355.3 millones) y consecuentemente un elevado costo financiero; con capital de trabajo deficitario, problema que se presentó notoriamente en 1998, llegando a su punto crítico en 1999; no obstante, la compañía mantenía saldos importantes por cobrar a una empresa afiliada. Igual situación se observa en sus indicadores de solvencia patrimonial, configurándose de esta manera su insolvencia ysu incapacidad para asumir nuevas obligaciones y poder cumplir con ellas.

94.4. La rentabilidad obtenida en el ejercicio de 1997, se vio afectada a partir de 1998, dado que la rentabilidad desde el punto de vista del patrimonio cayó mostrando cifras negativas Idéntico comportamiento se observa en la rentabilidad de las ventas, mostrando cifras negativas a partir de 1998, alcanzando su punto crítico en el año 2000. Paralelamente los costos directos de la empresa se incrementaron en casi 60\% entre el año 1997 y el año 2000; mientras que los gastos operativos, tuvieron un incremento pero menos significativo, más estable"

94.5. Finalmente, en sus conclusiones se señala que "Tercera: (...) se ha determinado, que los aumentos de capital social habidos en el período analizado, corresponden a aumentos efectuados por los socios tradicionales de la sociedad y se encuentran plenamente identificados y legalmente perfeccionados"

94.6.De todo ello se puede inferir que la empresa Compañía Peruana de Radiodifusión Sociedad Anónima - Canal cuatro, presentaba grandes deudas y poco dinero para afrontarlas, lo que abona hace razonable y hasta entendible que su accionista mayoritario haya visto con muy buenos ojos el ofrecimiento realizado por Vladimiro Montesinos Torres para entregarle dinero de procedencia estatal, a cambio de que se alinee con el gobierno, con lo cual podría mejorar su situación financiera al interior de la empresa, habiendo expresado en un momento del interrogatorio el acusado José Enrique Crousillat López Torres, ante una pregunta de la defensa del Tercero Civilmente Responsable: "Como Presidente del Directorio entre el año noventiocho y dos mil, cuál era la situación financiera de la compañía Peruana de Radiodifusión, era buena o se iba deteriorando? DIJO: Que, se iba deteriorando a partir de la recesión que hubo en el país', lo que se condice con el contenido de la pericia de parte ofrecida por la empresa Compañía Peruana de Radiodifusión Sociedad Anónima - Canal cuatro.

94.7. Esta misma situación nos permite sostener que dado que la empresa no obtenía rentas, sino que sus ganancias se iban en pagar deudas societarias, los accionistas no obtenían ganancias, por lo cual el ofrecimiento de dinero por parte de Vladimiro Montesinos Torres era doblemente beneficioso, pues también les servía para tener ingresos extras para aplicarlos a sus gastos o adquisiciones particulares, lo que explica que a pesar de no tener ganancias provenientes de su principal negocio hayan adquirido inmuebles valiosísimos, los que han sido incautados en la presente causa, pues precisamente esta situación determina que el dinero con que han sido adquiridos provenía de fondos públicos.

94.8. Sobre el ingreso del dinero recibido por José Enrique Crousillat López Torres y por José Francisco Crousillat Carreño a la contabilidad de la empresa Compañía Peruana de Radiodifusión Sociedad Anónima - Canal cuatro, es del caso indicar que ello no se ha podido determinar de manera directa, es decir, no se ha encontrado algún registro que indique de manera clara y cierta que ello se haya producido, pues dado el carácter ilícito de tales fondos por su origen es altamente improbable que ello se ingrese de manera tan cándida a la contabilidad de la empresa, por lo que es altamente probable que se haya producido vía aumento de capital, como el realizado en la junta de accionistas de la empresa Compañía Peruana de Radiodifusión Sociedad Anónima - Canal Cuatro, el dos de noviembre de mil novecientos noventinueve, donde se aprobó la capitalización de obligaciones que tenía la empresa respecto a José Enrique Crousillat López Torres por un monto ascendente a novecientos noventidós mil dólares americanos.

94.9. De otro lado, que el dinero haya, o no, 
ingresado al canal es relevante relativamente pues la discusión principal se centra en determinar sí los dependientes José Enrique Crousillat López Torres y José Francisco Crousillat Carreño, quienes actuaban en representación de la empresa Compañía Peruana de Radiodifusión Sociedad Anónima - Canal cuatro, al realizar el acuerdo ilícito con Vladimiro Montesinos Torres causaron un daño, por lo que verificado ello, la imputación de responsabilidad civil se produce en función a un factor de atribución objetivo.

Cabe agregar que los argumentos del Tercero Civilmente Responsable, en el sentido de que José Francisco Crousillat Carreño, ha causado daños a dicha empresa, que la han conducido a una situación económica desastrosa, en nada enervan la responsabilidad civil pues tales asuntos deben ventilarse en otra vía.

Ahora bien, corresponde ingresar a considerar el caso de la Compañía Peruana de Radiodifusión Sociedad Anónima respecto a la imputación de responsabilidad en cuanto a la conducta delictiva realizada por José Francisco Crousillat Carreño y José Enrique Crousillat López Torres, a fin de verificar si concurren los tres elementos y así arribar a una conclusión sobre esta materia.

97. En cuanto al primer elemento, es decir, la relación de subordinación, es manifiestamente claro que José Enrique Crousillat López Torres durante el desarrollo del delito imputado, esto es peculado por apropiación, ha actuado en función a una relación de subordinación entre él y la Compañía Peruana de Radiodifusión Sociedad Anónima, dado que era su accionista principal, dueño del noventinueve por ciento del accionariado, además de ejercer el cargo de Director General de dicho medio de comunicación, resultando por demás innegable que cuando negoció interposita persona, con Vladimiro Montesinos Torres, es decir, mediante el concurso de su coinculpado e hijo José Francisco Crousillat Carreño, también accionista y director de dicha casa televisiva, los términos del acuerdo ilícito pactado en el año mil novecientos noventiocho, lo hizo no como un ciudadano cualquiera o como una persona natural, sino en su calidad de dueño de dicho medio de comunicación, siendo ello el motivo por el cual se produjo el acercamiento entre ambas partes, y en todo momento fue esta calidad la que determinó no solo la consecución del concierto de voluntades, sino también su ejecución.

98. Es más, cabe afirmar que todos los elementos probatorios apuntan a verificar que cuando Vladimiro Montesinos Torres busca relacionarse con José Enrique Crousillat López Torres y con José Francisco Crousillat Carreño, es en el entendido, materialmente cierto, de que cualquiera de ellos procedía en nombre y representación del Canal Cuatro (Compañía Peruana de Radiodifusión Sociedad Anónima) dado que lo pretendido por Montesinos Torres era lograr asegurar por esta vía el control de la línea editorial de dicho medio de comunicación para sus propios fines de grupo, lo que resulta mucho más claro si consideramos que tales compromisos se ejecutaron en la realidad, conforme es de conocimiento público, lo que prueba que el proceder de dichos acusados se desenvolvió en interés y representación de la empresa Compañía Peruana de Radiodifusión Sociedad Anónima-Canal Cuatro.

99. En cuanto al segundo elemento, es decir que el subordinado cause daños, se tiene que también tal elemento concurre, pues José Francisco Crousillat Carreño y José Enrique Crousillat López Torres, con su complicidad en el delito contra la Administración Pública Peculado por Apropiación, cometidos por Vladimiro Montesinos Torres y con la autoría por parte de José Francisco Crousillat Carreño en el delito de Asociación llícita para Delinquir, se han causado serios y graves daños al Estado pues fueron tales personas, que actuaban en nombre y representación real de la empresa Compañía Peruana de Radiodifusión Sociedad Anónima - Canal cuatro, para las que Montesinos Torres se apropió de caudales públicos, habiéndole pagado astronómicas sumas de dinero estatal en virtud a un contrato ilícito, a efectos de tener el control de

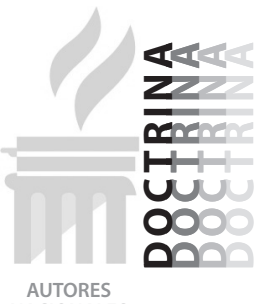
AUTORES
NACIONALES 
la línea editorial del canal cuatro, causando con ello un grave perjuicio al Estado, lo que ha sido también aceptado tácitamente por el propio Crousillat Carreño, al acogerse a la Terminación Anticipada de los Debates Orales por conformidad con la acusación fiscal.

100. Finalmente, el elemento de la relación de causalidad, se encuentra suficientemente acreditada, con todo lo antes expuesto, pues el dinero que el Estado perdió, fue a parar a manos de José Enrique Crousillat López Torres y de José Francisco Crousillat Carreño, reiteramos, no por ser ciudadanos cualquiera, sino en tanto representantes reales de la Compañía Peruana de Radiodifusión Sociedad Anónima - canal Cuatro, quedando así establecida la concurrencia de todos los elementos de esta responsabilidad.

101. De todo ello concluimos que a la empresa Compañía Peruana de Radiodifusión Sociedad Anónima - Canal cuatro le alcanza responsabilidad en calidad de Tercero Civilmente Responsable respecto a los acusados José Francisco Crousillat Carreño y José Enrique Crousillat López Torres, siendo solidariamente responsable con ellos" (el subrayado es mío).

Esta decisión, que cuenta con el voto discordante del Vocal Ricardo Brousset Salas, me genera sentimientos encontrados: por un lado se sigue ad pedem literae mi posición al individualizar los elementos constitutivos de la responsabilidad civil, las funciones de la responsabilidad civil, los criterios que diferencian la responsabilidad subjetiva y objetiva, las características de la responsabilidad extracontractual del principal ${ }^{34}$; por otro, sic et simpliciter, se omite groseramente la fuente donde se obtuvo la información. En verdad, la realidad supera la imaginación del académico: este es un evidente supuesto de plagio de un texto, cometido ni más ni menos por vocales, en la redacción de una sentencia ${ }^{35}$.

\section{VIII.REFLEXIÓN FINAL}

Se ha constatado cómo el plagio es una suerte de cáncer generalizado en nuestra sociedad: lo hace tanto el vocal de la Corte Superior como el reconocido escritor. De esta enfermedad no escapan las investigaciones jurídicas, sea en publicaciones que circulan en nuestro medio, como en la simple monografía o trabajo que hace el alumno universitario. En este último caso, se debe tener en cuenta que no se trata sólo de un supuesto que simultáneamente genera responsabilidad civil, penal o administrativa: es principalmente, una falta moral y ética.

Es justamente al componente ético, al que quiero hacer hincapié: se debe tener en cuenta que esta responsabilidad no sólo es del alumno o del tesista, es también una responsabilidad del asesor. Las autoridades universitarias deberían ser más firmes en lo que a control de las investigaciones se refiere y sancionar no sólo a los alumnos que cometen esta falta, sino también a aquellos docentes que se comprometen a asesorar y revisar estos trabajos. Esta es una tarea que tiene que ser asumida con seriedad y si se incumple, o cumple defectuosamente, merece la sanción correspondiente.

34. Me estoy refiriendo a mi Derecho de la Responsabilidad Civil, Tercera Edición, Gaceta Jurídica, Lima, 2005, que circulaba en ese entonces.

35. Ello ya había sido advertido por una atenta doctrina que observa que "la honestidad intelectual es exigible para todos y esta exigencia es mayor en los jueces. Si los jueces no actúan honestamente, copiando sin citar la fuente, están transmitiendo una peligrosa forma de elaborar argumentos. Decimos "peligrosa" porque cada argumento se desarrolla en un contexto concreto y con sus propios fundamentos" (MORALES HERVIAS, Rómulo. Persona jurídica como tercero civilmente responsable. Una infeliz o feliz vinculación entre el Derecho Civil y el Derecho Penal. En: Diálogo con la Jurisprudencia, No. 96, Año 12, Gaceta Jurídica, Lima, setiembre 2006, p. 69). 